\title{
Humanities quantorium as a technological digital environment
}

\author{
Maxim Bakhtin 1,*, Leonid Laptev², Oksana Shamigulova ${ }^{3}$, Rida Zekrist ${ }^{3}$, Salavat \\ Musifullin ${ }^{3}$, and Roman Tkach ${ }^{4}$ \\ ${ }^{1}$ International Professorial Club (Italia), 97100, via Velardo, 35, Ragusa, Italia \\ ${ }^{2}$ Modern Humanitarian Academy, 109029, Nizhegorodskaya str., 32, p. 4, Moscow, Russia \\ ${ }^{3}$ Bashkir state pedagogical University named after M. Akmulla, 450000, st. October Revolution, 3a, \\ Ufa, Russia \\ ${ }^{4}$ Pacific National University, 680000, Karl Marx Street, 68, Khabarovsk, Russia
}

\begin{abstract}
The purpose of the article was to formulate a general problem and clarify the hypothesis of research on the design of a humanitarian quantorium as a technological digital environment for the formation of teacher competencies in the subject areas "History" and "Social Sciences", to determine the set and content of teacher competencies in the field of applying humanitarian education technologies. The leading research methods described in this article were the method of foresight design, the method of expert panels and methods for the diagnostic study of occupational deficiencies. The materials presented in the article contain a description of the results of a pilot study on identifying professional deficiencies of a history and social science teacher, a generalized, refined set and content of the future teacher's competencies in the field of applying humanitarian education technologies in a digital environment, a conceptual rationale for equipping a humanitarian quantorium as a technological environment for the formation of teacher competencies. In the substantiation, an integrated approach was applied, which allows to combine the content of humanitarian education, teaching technologies and digital means into a single innovative didactic space. The conclusions are drawn to the peculiarities of the application of the humanitarian quantorium model in the wide practice of professional training of history and social studies teachers for the implementation of the developmental capabilities of the subjects of the humanitarian cycle and improving the quality of humanitarian education.
\end{abstract}

\section{Introduction}

The digitalization of modern society makes it necessary to revise the didactic foundations of education at all levels. In our article we are talking about liberal arts education, namely about teaching disciplines of the educational field "Social Sciences" at school and the

Corresponding author: universdoktor@gmail.com 
readiness of a modern history and social studies teacher to learn in a new digital environment. Didactic approaches, methods, techniques, technologies and teaching aids in the context of global access to information must be developed and adapted to a situation in which the textbook and the teacher's word are not the only source of information and knowledge either. In this context, the most vulnerable is humanitarian education, the main function of which is to create meanings, conditions for the development of the cultural experience of mankind, the formation of a person's worldview and values. At the same time, the problem lies not in the availability of various sources of information and not in the variety of purposes of its creation, but in the readiness of a person to process and verify information presented in various sign systems, to understand and create meanings, since the development of digital technologies requires new skills in working with information.

In this situation, the worldwide decline in the popularity of humanitarian knowledge and education, the diminution of the role of humanitarian knowledge in the development and further progress of a person and society create contradictions between the need to preserve general humanitarian values and human development in a person and insufficient attention to the implementation of the educational opportunities of humanitarian education, teacher training to teaching the subjects of the humanitarian cycle in an updated digital educational environment, the development of teaching methods for future teachers, the implementation of a technological approach to teaching, the development of new teaching aids and the creation of a modern didactic infrastructure.

In this regard, the problem of finding modern tools of humanitarian education for personal development and creating conditions for teachers to master these tools is obvious. In our opinion, liberal arts education technologies can become such tools. In the context of our research, we understand the technologies of humanitarian education as a system of effective forms, methods and means of forming personal value attitudes, soft-skills and hard-skills in the process of teaching subjects of the humanitarian cycle. But in order for such a tool to "play" in the new digital educational environment, an integrated approach is important, which allows combining the content of liberal arts education, teaching technologies and digital means into a single innovative didactic space - quantorium. At the same time, the quantorium is designed to maximize the possibilities of digital means in the development of humanitarian education technologies and the preparation of teachers for their use.

The pedagogical humanitarian quantorium is understood as an innovative model of the formation of the teacher's competence in the subject area "Social Sciences" in the application of humanitarian education technologies, combining the predicted results of teacher training, the content of liberal arts education, forms, methods, technologies and digital innovative teaching aids. We assume that in order to ensure the effectiveness of teacher training for the implementation of the educational potential of humanitarian education technologies in the context of digitalization, it is necessary to design and implement in the practice of training a pedagogical humanitarian quantorium as a digital technological environment for the formation of teacher competencies, which makes it possible to broadcast the practice of applying humanitarian education technologies based on digital means. Note that the very concept of "pedagogical quantorium" was first introduced into the humanitarian scientific thesaurus by researchers of the Bashkir State Pedagogical University - OA Shamigulova. and Musifullin S.R.

The ideas of transforming the educational environment in the context of digitalization are increasingly emerging as one of the current trends in pedagogical science and educational practice. At the same time, we are close to the point of view of the researchers Stéphanie Philippe and the team of authors of the article "Multimodal teaching, learning and training in virtual reality: a review and case study", as well as Zois Koukopoulo, Dimitrios Koukopoulos, who note that updating the educational environment along the path 
of digitalization leads an indispensable update of the teaching strategy, a more active introduction of a technological approach to organizing the cognitive activity of students, the use of educational technologies in combination with digital means [1,2]. General ideas about the development of education technologies and their adaptation to the digital environment to obtain optimal educational results were reflected in the research of Brandon Olszewski, Helen Crompton on providing adequate opportunities for students to acquire digital age skills [3], Anja Hawlitschek, Sven Joeckel - on methods of optimal use educational opportunities of digital games to enhance the cognitive activity of students and improve the quality of learning [4], Qiulian Song Ling He, Xiaoqiang $\mathrm{Hu}$ - on the effectiveness of the use of interactive educational technologies and digital tools in teaching history [5], Shamila Janakiraman and a team of researchers - on the possibilities the use of digital games to improve the quality of education [6].

In our study, we use the foresight methodological toolkit in order to design a complex of pedagogical conditions aimed at developing the future teacher's competencies in the application of humanitarian education technologies in the modern digital environment. It was assumed that the set of conditions should combine the predicted results of teacher training in the subject area "Social Sciences", the content of liberal arts education, teaching technologies and digital means.

In preparation for the study, we found that the idea of quantoriums in the form of children's technology parks "Quantorium" has been implemented in Russia since 2016 in the system of additional education for children. In this context, children's technology parks are defined as an innovative environment that forms inventive, creative, critical and product thinking in children, implemented on the basis of organizations that provide training in additional general developmental programs of natural science and technology. The existing experience of the quantoriums, of course, must be taken into account in the system of training future teachers. At the same time, the training system itself, including the entire range of conditions for its functioning and infrastructure, should be of a forward-looking nature. However, we note that the provision of educational services in children's quantoriums is carried out according to programs of natural science and technical orientation. At the same time, humanitarian quantifiers are absent in the Russian educational space.

Purpose of the study: So what should future teachers of history and social studies learn, because in the digital world, most of the routine and impersonal work will be the concern of computer systems?

There are many discussions that do not boil down to the idea of increasing the volume of materials being studied. Alternative solutions are to transfer to students the knowledge that is more necessary for life in the digital world, teach them to apply this knowledge in various ways, to form in them the necessary abilities, personal qualities and the ability to learn.

To what extent employers and students are satisfied with this state of the educational system.

According to a survey of the international consulting company McKinsey, there is a large (twofold!) Discrepancy between the assessment of education by teachers of $74 \%$ (mostly positive) and the opinion of their clients: $38 \%$ of young people and $35 \%$ of employers (mostly negative - see Fig. 1 [7]).

The monitoring results show that the main problem of the research is rooted in this contradiction. Thus, the purpose of the study follows from the formulation of a general problem and consists in clarifying the hypothesis of research on the design of the humanitarian quantorium as an innovative model for the formation of teacher competencies in the subject areas "History", "Social Sciences", as well as in determining the set and content of teacher competencies in the field of technology application humanitarian 
education. At the same time, the list and content of competencies are the starting point for the design of the quantorium and are studied at the soft-skills and hard-skills level among students of a pedagogical university - future teachers of history and social studies and at the level of professional deficiencies of practicing teachers in this subject area.

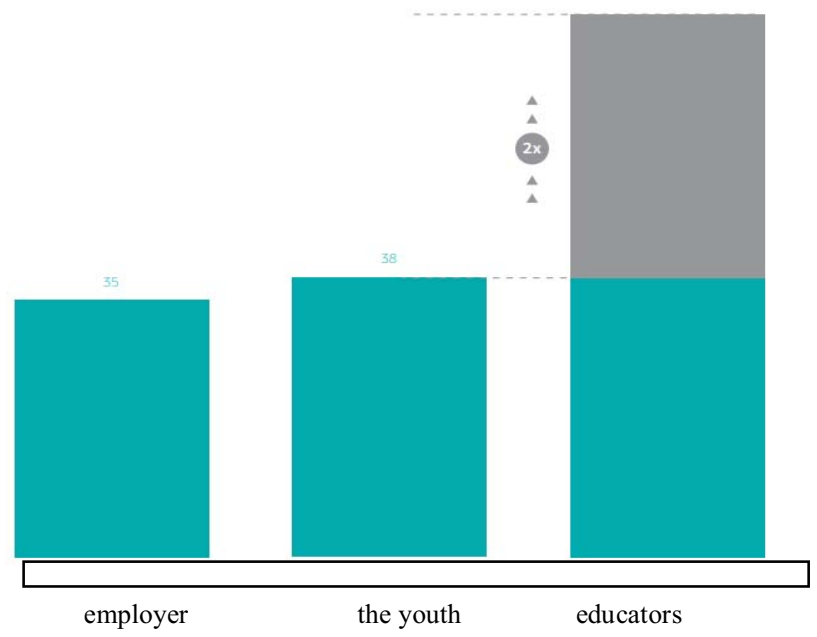

Fig. 1. Discrepancy between the assessment of education by teachers and the opinion of their clients.

\section{Materials and methods}

To achieve the set intermediate goals of the study, the foresight design method, the method of expert panels and the methods of diagnostic research of occupational deficiencies were used.

Determination of the set and content of teacher competencies in the field of application of liberal arts education technologies was carried out on the basis of the creation of a group of experts from among leading practicing teachers, graduate students with experience in teaching history and social studies in schools, researchers in the field of humanities (philosophy, history, sociology and pedagogy). The expert group was asked to consider the content of the teacher's competencies, taking into account the rapidly changing society, conditions and trends of modern education, challenges in the field of liberal arts education and digitalization. The expert group was asked to answer several sequential questions, both directly related to a given work result, and indirect ones, which make it possible to clarify the content of the predicted results in the context of the study: what is the role of liberal arts education in a digital society? What is the purpose of studying history and social studies in a modern school? What is the role of the subjects of the educational area "Social Sciences" in the formation of universal learning actions (skills of the future)? What educational technologies are most in demand in the practice of teaching history and social studies? What risks in ensuring the effectiveness of teaching history and social studies can be identified? What new learning opportunities are associated with the development of the digital environment? What professional skills are required for a teacher to effectively realize the educational potential of these subjects in the context of the development of the digital environment?

We used the latest information and analytical developments and materials (!). The method of expert panels made it possible to unite representatives of different fields of activity and, directly, representatives of the employer who confirmed the existing professional deficiencies, both novice teachers in the field of applying the technological 
approach to teaching, and teachers with experience. One of the reasons for these deficits is a change in educational paradigms, the transition from knowledge to an activity paradigm, which in the real practice of the mass school is still being implemented.

We compared the received expert opinion with the data of various studies. Currently, external consumers of services of higher educational institutions (employers), including pedagogical universities, raise the problem of insufficient formation of professional competencies among graduates.

According to research on the competencies of history and social studies teachers within the framework of the development of the national system of teacher growth (NSDS), more than $30 \%$ of teachers demonstrate a low level of methodological competence directly related to the competent and effective use of educational technologies.

Based on the results of the work of experts and the analysis of national studies of pedagogical competencies, we have compiled a primary version of the competence model of a future teacher, which allowed us to develop a diagnostic questionnaire for graduate students - future teachers of history and social studies and practicing teachers.

Based on the results of the work of experts, analytical materials and approximate educational programs of general education, we have compiled a primary version of the competence model of the future teacher of history and social studies, highlighting educational results at the level of general universal soft-skills and professional skills of a teacher of history and social studies (hard-skills):

- general humanitarian skills (soft-skills level):

- development of a humanitarian outlook;

- development of skills to carry out a comprehensive search, systematization and interpretation of social information on a specific topic from original unadapted texts (philosophical, scientific-historical, political, journalistic, regulatory legal acts, etc.) using modern means of communication (including Internet resources);

- development of skills to work with information presented in various sign systems;

- development of media competence (skills of critical thinking and verification of information from various sources, to understand the role of information in modern social processes, to create information and present it in various sign systems);

- development of the ability to conduct a discussion on topical issues, formulate your point of view, build arguments and counterarguments based on theoretical and empirical knowledge, oppose;

- development of communicative competence and dialogue thinking (the ability to carry out constructive interaction of people with different beliefs, cultural values; national, ethnic and religious affiliation based on respect for the culture and traditions of the peoples of Russia, national values of modern Russian society: humanistic and democratic values, ideas of peace and mutual understanding between peoples, dialogue of cultures);

- development of skills to carry out individual and group research on historical and social issues (research competence), to form ideas about the methodology of social and humanitarian research, skills in applying methods of social and humanitarian research in solving project problems.

Professional skills of a teacher of history and social studies (Hardskills level):

- development of systemic historical knowledge, understanding of the place and role of Russia in world history, the history of the region in the history of Russia and the world, the historical conditioning of local events and phenomena;

- development of cartographic skills and mastery of the skills of cartographic interpretation of socio-economic characteristics of various territories;

- development of skills to work with various types of historical sources, the ability to independently analyze the documentary base on historical topics; 
- the formation of the ability to design subject content, the ability to design thematic exhibitions and excursions in AR and VR mode;

- development of skills to apply historical knowledge in professional and social activities, multicultural communication;

- development of skills in organizing historical reconstruction in digital format with the involvement of various sources.

- the formation of ideas about the main trends and possible prospects for the development of the world community in the era of digitalization;

- the formation of skills to apply a complex of knowledge in the field of social science, economics, cultural studies, etc. for understanding and evaluating social events in Russia in different periods;

- the formation of legal thinking and knowledge about the general principles and norms governing the state structure of the Russian Federation, the constitutional status of state power and the system of constitutional rights and freedoms in the Russian Federation, mechanisms for the implementation and protection of the rights of citizens and legal entities;

- development of ideas about the methodology and methods of social cognition, the ability to organize mini-research in the context of the personal social experience of students;

- development of civic literacy, the ability to apply social science knowledge in everyday life and to form these skills among students: legal literacy, financial literacy, electoral literacy, information literacy and others;

- the development of skills for assessing social information, the ability to search for information in sources of various types for the reconstruction of missing links in order to explain and evaluate various phenomena and processes of social development;

- development of skills to work with statistical, factual and analytical information, the ability to independently analyze and interpret data to solve theoretical and applied problems.

\section{Results}

As we can see, from the obtained pilot competence model, one of the most important complex skills formed in the process of studying humanitarian subjects is the ability to work with information (including various sources and presented in various sign systems). Based on the results obtained, we needed to find out whether graduate students and practicing teachers know how to form these skills. Based on the methodological relationship of techniques and skills, a questionnaire was compiled. The survey was conducted among 54 graduate students - future teachers of history and social studies and 112 practicing teachers of various age categories (among them are young teachers and teachers with more than 20 years of experience). The survey results are presented in tables 1 and 2 , respectively.

The survey data make it possible to determine that the types of tasks aimed at the formation of skills to work with the text, as the main information unit, were systematically applied in practice by only a fifth of the students and significantly fewer practicing teachers.

We asked the same groups of respondents to answer two additional questions:

- How, in their opinion, the use of modern digital equipment in teaching history and social studies can influence the formation of skills to work with various sources of information? At the same time, the respondents could choose several answers from the proposed ones: 1) will increase the motivation of students for this type of work in the classroom; 2) will ensure the effectiveness of the use of didactic techniques for working 
with information; 3) will ensure the quality of didactic materials (sources) for the lesson; 4) will not significantly affect (Fig. 2. dark color represents students of 4-5 courses, light color - subject teachers).

Table 1. The use of certain types of tasks for working with the text during the period of pedagogical practice (in history and social studies).

\begin{tabular}{|c|c|c|c|c|c|c|c|}
\hline \multirow[b]{2}{*}{ Frequency of application } & \multicolumn{7}{|c|}{ Types of tasks with a detailed answer } \\
\hline & 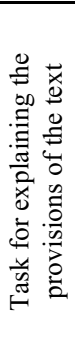 & 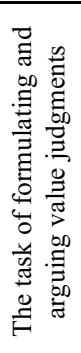 & 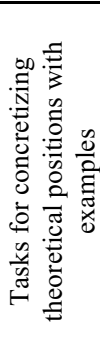 & 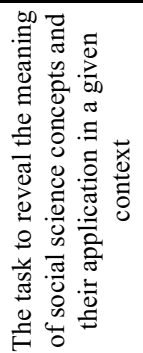 & 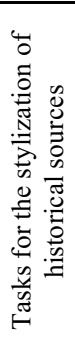 & 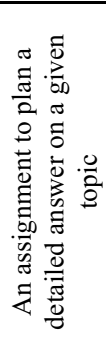 & 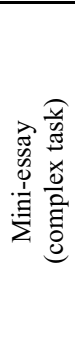 \\
\hline systematically & $22 \%$ & $21 \%$ & $22 \%$ & $26 \%$ & $16 \%$ & $32 \%$ & $45 \%$ \\
\hline sometimes & $59 \%$ & $57 \%$ & $33 \%$ & $41 \%$ & $11 \%$ & $48 \%$ & $42 \%$ \\
\hline practically did not use & $19 \%$ & $22 \%$ & $45 \%$ & $33 \%$ & $73 \%$ & $20 \%$ & $13 \%$ \\
\hline
\end{tabular}

Table 2. The use of certain types of tasks for working with text in the process of organizing the teaching of history and social studies.

\begin{tabular}{|c|c|c|c|c|c|c|c|}
\hline \multirow[b]{2}{*}{ Frequency of application } & \multicolumn{7}{|c|}{ Types of tasks with a detailed answer } \\
\hline & 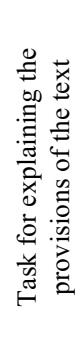 & 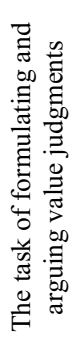 & 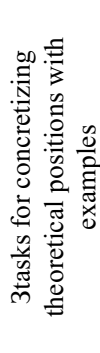 & 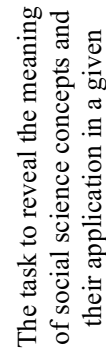 & 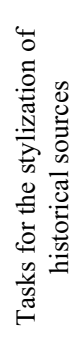 & 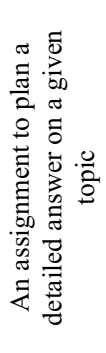 & 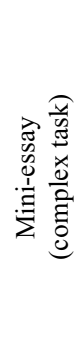 \\
\hline systematically & $16 \%$ & $19 \%$ & $22 \%$ & $21 \%$ & $21 \%$ & $26 \%$ & $19 \%$ \\
\hline sometimes & $51 \%$ & $51 \%$ & $43 \%$ & $51 \%$ & $43 \%$ & $32 \%$ & $35 \%$ \\
\hline practically did not use & $33 \%$ & $30 \%$ & $35 \%$ & $28 \%$ & $36 \%$ & $42 \%$ & $46 \%$ \\
\hline
\end{tabular}
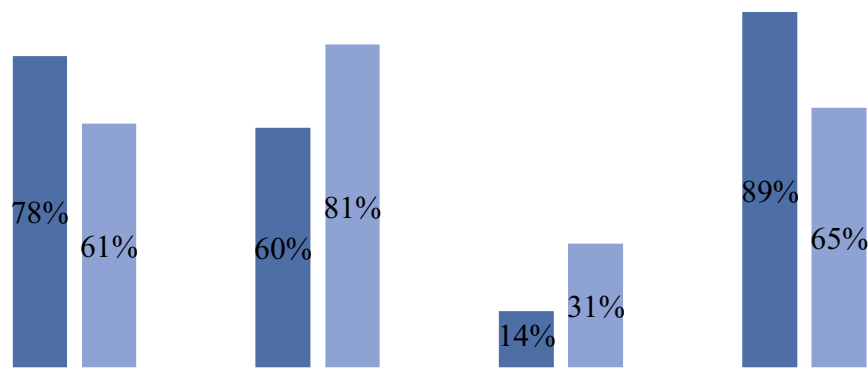

Fig. 2. Results of the survey on the problem of the formation of skills to work with varioussources of information. 
- Do you have a sufficient, in your opinion, level of professional competence to use modern digital equipment in organizing work with various sources of historical and social information in the classroom? (Fig. 3 - from left to right: yes, I own; partially I; I do not; dark color represents students of 4-5 courses, light color - subject teachers).

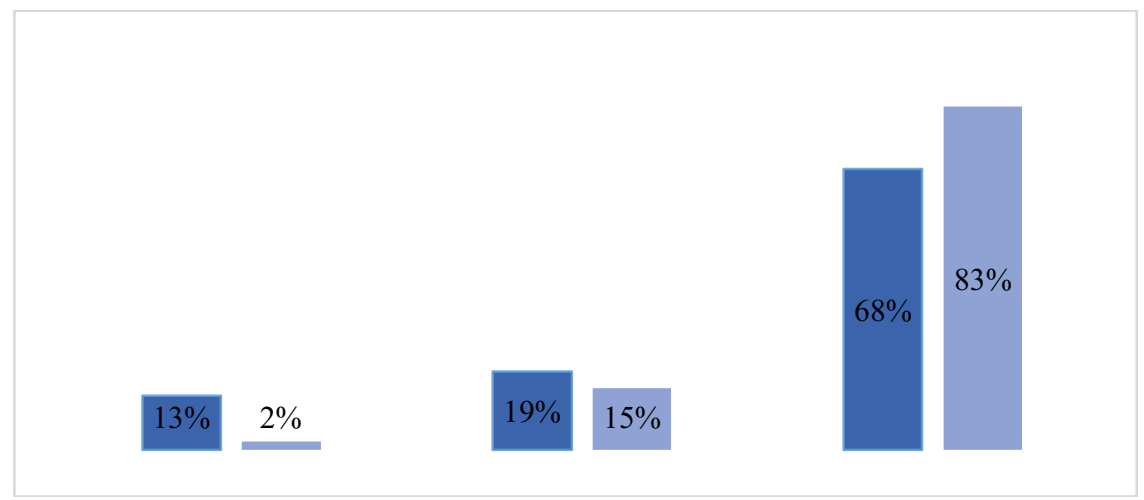

Fig. 3. Results of the survey on the problem of mastering the level of professional competencies.

To discuss the results of the survey, the method of expert panels was also applied. Analyzing the results of the survey on the use of tasks with text and other sources of information, a number of expert teachers suggested that the reason for the non-use of such tasks by the majority of teachers in the systematic practice of such tasks is the large time spent on the development of the tasks themselves, the selection of sources, as well as for the students to complete this kind of tasks on lesson. Comparing the answers of the respondents about the use of methods of working with information and the role of modern digital equipment, it becomes obvious that both groups of respondents have a positive opinion about the possible effects of using special equipment in organizing work with sources. In this regard, the problem of competence-based professional deficits of both practicing teachers and future teachers in the implementation of this work is more acute.

Based on the results of the intermediate research data, a generalized, refined set and content of the competencies of the future history and social science teacher in the field of implementation of humanitarian education technologies were determined. Summarizing the results of research on the applied methods and techniques of teaching history and social studies, as well as an analysis of modern research on the quality of education, it can be noted that modern trends in the development of society shift the emphasis on the need to form:

- Softskills: humanitarian outlook, media literacy, DATA literacy, polylogical thinking, research technologies;

- Hardskills: skills of cartographic interpretation of socio-economic characteristics of various territories; the ability to work with a historical graph database; the ability to apply polylog technologies in the analysis of historical and social science sources; the ability to design content, including in AR and VR; skills in organizing historical reconstruction in digital format; probabilistic thinking (forecasting skills and foresight design); the ability to organize microsocial research in the context of students' personal social experiences; the ability to design the application of the technology of humanitarian education in teaching the subjects of the humanitarian cycle.

In order to determine effective pedagogical technologies that make it possible to form these competencies, an analysis of modern educational technologies in the field of humanitarian education was carried out.

At the same time, we proceeded from the fact that pedagogical technology should bring the learning environment closer to professional conditions and necessarily involve activities 
to resolve the problems of educational practice, that is, the process of solving problems that allow one to gain new knowledge about pedagogical reality, since the Softskills and Hardskills of the teacher are formed and manifests itself in solving professional problems. In the course of the study, a portfolio of effective technologies was identified that must be used in the formation of competence and with which future teachers of history and social studies should be armed (Technology for the formation of critical thinking, polylog technology, gamification in reconstruction and foresight design, case technology, foresight technology, design -thinking, editing and Machine Learning).

Analysis of the research identified the need to clarify the research hypothesis and the concept of "Pedagogical quantorium". In the logic of our research, it can be argued that the development of supra-professional competencies is facilitated by the mastering of humanitarian technologies by teachers. At the same time, the technology of humanitarian education is considered by us as a promising vector of innovative development of education, because it allows the teacher to realize both professional and professional competencies that are in demand by a modern transforming society. For the implementation of the technology of humanitarian education, it is necessary to transform the consciousness of all subjects of the complex process of interaction. For this, it is necessary to create an environment for the integration of digital methods into the traditional learning process. This environment defines the pedagogical quantorium as an innovative didactic space for the formation of the future teacher's competencies, created on the basis of a cluster of methodological quantums - laboratories that conceptually reflect the functionality and specificity of academic subjects of the educational field "Social Sciences", educational opportunities of the humanitarian subject line in the development of softskills and Hardskills.

The search for conceptual solutions for creating a humanitarian quantum and training future teachers in the subject area "Social Sciences" is associated with the need to develop humanitarian thinking, civic identity, media competencies as personal general humanitarian skills of a person of the future, as well as subject humanitarian knowledge aimed primarily at the formation of holistic ideas about a person and a digital society in the context of historical and cultural development. Therefore, the concept assumes the division of quantum into the following locations: "Laboratory (quantum) of general humanitarian skills of the XXI century", "Laboratory (quantum) of interactive history", "Laboratory (quantum) - A person in a digital society", "Laboratory (quantum) -" Homosimbolicum "'".

The content and functional content of the locations will allow organizing the educational space, dividing groups of students and structuring the process of mastering skills in a methodological sequence.

Based on the analysis of modern requirements, the content and methodological foundations of quanta are determined. Quantum will include basic equipment for research in history, social science, law, economics, as well as specialized tools for demonstrating and applying relevant technologies at the intersection of social, humanitarian and digital sciences:

- projection equipment and projects for augmented reality (design of events on historical and social science topics);

- interactive installations for design solutions in the framework of the subject content and topics of additional education programs ("interactive archeology", "interactive medieval studies", "interactive political science", "digital economy", etc.);

- interactive maps (physical, political, thematic (local-historical), etc.);

- interactive desktops (for visualizing historical events, social objects; organizing individual and group project work);

- AR and VR equipment;

- audio guides (virtual excursion design), mobile apps and other tools. 
Equipping a quantum, in our opinion, should allow for a wide range of methodological solutions aimed at ensuring the achievement of subject and metasubject (universal) skills in accordance with the requirements of the Federal State Educational Standard of General Education, projecting the teacher's professional competencies to ensure the desired results. Therefore, in the basis of the design of the technical equipment of the quantum, one cannot but take into account the interconnection of techniques and skills being formed, continuity and phasing in the formation of skills, intracourse and intersubject connections. To be ready to search for and implement methodological solutions at a high professional level, the future teacher must master the skills being formed perfectly. Among them, as the previously described analysis shows, metasubject skills are especially relevant for modern humanities students. These are the ability to carry out a comprehensive search, systematization and interpretation of social information on a specific topic from original unadapted texts (philosophical, scientific-historical, political, journalistic, regulatory legal acts, etc.) using modern digital means of communication; media competence (skills of critical thinking and verification of information from various sources, creation of information and its presentation in various sign systems). Among the subject professional skills, it is important to highlight the skills associated with teaching history and social studies in a digital environment. This is the ability to design subject content, thematic exhibitions and excursions in AR and VR mode, the ability to apply historical knowledge in professional and social activities, multicultural communication; skills of organizing historical reconstruction using various digital sources; civic literacy, including legal, financial, electoral, legal media security skills; the ability to work with statistical, factual and analytical information in a digital environment.

Based on the planned results, the quantum equipment for training teachers in the social sciences subject area may include such elements as: touch interactive table for developing interactive maps, books of memory or books of public figures, reproduction of photo and video content; interactive installations, the software of which will allow for the selection of subject content, mastering digital skills in the design of AR and VR objects; AR and VR dual-use kit; document camera for projecting various text and visual sources.

As an example, we will give a methodological description of the laboratory (quantum) "Homosimbolicum", which is aimed at studying the processes of development of the cultural potential of the individual, technologies for the formation of practical thinking and experiences of the formation of the phenomenon of cultural subjectivity, focused on the production of high-quality interdisciplinary scientific thought that finds its application in specific social practices ... The main feature of the Laboratory functioning model is a combination of research formats, collaboration, eventfulness and co-creation.

Researcher R. Zekrist refers to the work of E. Cassirer, pointing out that the structure of the model consists of a number of competencies, the key of which is digital multiculturalism [8]. To determine the contextual educational goals and objectives of the Laboratory, it is necessary to briefly consider the theoretical foundations of the multicultural training of future teachers. To do this, we will formulate a basic hypothesis, taking into account the entire "alien" line of "semantization" - "socialization" - "cultivation" of the student's personality, which consists in the fact that the philosophical meaning of such a definition should be focused on identifying the specific role of culture as a historically invariant mediator (conductor, "Translucent mirror") between the alien life of man in society and his natural, psychophysical.

It is important to note that theoretical certainty must be combined with competence, including interdisciplinarity (transdisciplinarity), which makes it possible to keep in the focus of research attention all the necessary subjects included in the compendium of a cultural person: 
- the subject of human psychology - the sources, processes and results of the direct and mediated (consciousness and unconscious, images and plans, motives and goals of behavior, etc.) of the individual's interaction with himself and the phenomenal world;

- the subject of sociology - the sources, processes and results of direct and mediated (conventions, public masks, hierarchical and temporal gaps, radii of personal influence, etc.) human interaction with people around him and society as a whole;

- the subject of cultural studies - sources, processes and results of mediated (through traditions, cultural monuments and samples, etc.) interaction of individuals and social groups with modern and historical humanity.

Culture has emerged as a great mediator between the obvious and the hidden, truth and falsehood, ordinary and transcendent, frank and secret, direct and deceitful, existential and apparent, past and new, self-awareness and self-expression, etc. The symbol is formed and perpetuated within the framework of culture with chaotic intensity. and metaphor, sign and riddle, myth and rite, iconic image and mysticism of numbers, utopia and prophecy, acting and role, mask and jargon, etc.

It is in the variety of "mediators-mirrors" that the specifically human experience of identifying and distinguishing between individuality and sociality is constituted on the basis of the triunity of acts of action, thinking and feeling, as E. Cassirer wrote about [9].

The era of digital culture is called the era of post-literacy - this is a cultural era characterized by the presence of communication gaps between people with a limited set of forms of literacy, which complicates intercultural and intergenerational cultural dialogue, this is the program setting of the international conference "Communication trends in the post-literacy era: polylingualism, multimodality, polyculturalism "[10].

New communication trends are embodied and communicated / manifest themselves in cultural languages. Moreover, each process (act) of culturally significant human interaction consists of three components, each of which is composed of many others that determine its specific pattern.

Contextual educational goals and objectives of the Laboratory form the competence of digital multiculturalism of future teachers through a mechanism for resolving the following problematic issues: the ways of existence of each of the studied languages, with the help of which media (intermediaries) texts created in these languages are broadcast, how complex multimodal, polymorphic ("Multimodal") texts in modern culture, as the transition from reading a predominantly printed monomorphic ("monomodal") page to reading a multimodal text in media art, design, and the media is realized [9].

Thus, a small analysis of the model of the functioning of the Laboratory (quantum) "Homosimbolicum" confirms the truth of A. Schleicher's position [11]: "innovation in education is not just a matter of introducing new technologies into more classrooms; it is about changing approaches to learning so that students acquire the skills they need to thrive in a competitive global economy.

\section{Discussion}

The discussion review of the sources allowed us to summarize the existing research in this direction and describe the key trends that determine the current state of the problem.

When considering the studies by Igor Ivanov, Jesennia Cárdenas Cobo, Marina Kosonogova, aimed at developing methodological and applied solutions in the field of breakthrough education, let us pay attention to the method of modeling psychological and pedagogical processes based on developing learning in a digital learning environment, proposed by the authors, where the methodology of developing learning provides high rates of individualization of the educational process [12]. 
At the same time, in the case of using dishonest strategies in online learning, Marina G. Sorokova believes that it will be effective to turn to the method of cluster analysis [13], and when studying models of informal scientific communication of young scientists in the humanities and social disciplines using social networking tools, In the opinion of Elena Neupokoeva and the team of authors, we will apply an experiment based on the methodology of developing students' systems thinking based on a project-based approach in the process of online learning [14].

It is important to note that, as an element of a systematic approach, a mixed feedback environment that contributes to increasing the competence of future teachers has been studied by a number of authors using digital video as an example. A digital video environment can produce stronger effects than traditional face-to-face settings. A study by Christopher Neil Prilop and his colleagues showed how future teachers can be upgraded during a hands-on history and social studies class [15].

Researchers Panagiotis Psomos, Maria Kordaki, in their article "A new educational digital storytelling tool aimed at eliminating student misconceptions" [16], applied educational digital storytelling to the development of multimedia digital stories. The authors believe the new digital storytelling tool can help students create digital stories using the EducationalW (Ed-W) story grammar, develop a storyline for each step of the Ed-W story grammar separately, and combine multimedia files.

Digital Interactive Storytelling (DIS) and Educational History Games are two important tools in technology enhancing history learning that will benefit from their mutual collaboration: educational history games can make history courses more engaging and motivating for students, DIS provides learners with interactive and adaptive environment so that they can choose different plots and control the development of the story [17].

The study of such social technology as microblogging (Edmodo and Cirip), which is used to draw up a typology of mini-stories for students' electronic portfolios, is no less effective for the development of the future teacher's competencies. In particular, a number of authors [18] have explored how stories relate to social media, and thus technology, in terms of opportunities, challenges, benefits, constraints and risks.

For example, MariaKordaki[19] in her article draws attention to the advantage of educational modeling methodology (Ed-W methodology), which is suitable for developing storyboards for educational digital stories with a demonstration of the design of a specific digital story.

As studies show [20], work on the design of the social navigation infrastructure, the use of social navigation methods can provide valuable assistance in guiding future history and social science teachers to the most useful information. Social navigation works by processing traces of past user behavior and harnessing the collected "collective social wisdom".

Next, let us turn to the format of the technological digital environment studied by the authors for the formation of the future teacher's competencies and highlight the following possible platforms.

If in the article B. Mayer, D. Tantscher, Ch. Bischof [21] examines a digital learning and research factory with an interdisciplinary focus on vertical and horizontal IT integration, where the industrial Internet of Things (IIoT) is the key technology, while other authors explore the possibilities of using laboratories for virtual educational environments (VLE) [22].

CathiaPapi points out that digital spaces sometimes seem incomplete or less attractive than commercial platforms or social media. In order to understand the technological preferences of prospective teachers, the author asks the question: "To what extent are these students more likely to prefer and use this or that type of learning environment?" [23]. 
Well, to conclude the review, we point to FabLabs - a digital manufacturing laboratory serving as a platform for prototyping physical objects with wide educational, social and economic benefits through the exchange of knowledge between participants. Researchers [24] note that FabLabs enables innovation by leveraging the technological resources available in the space, stimulating the creativity of its participants, supported by implicit and explicit transfer of knowledge, and allowing the development of products and solutions based on personal projects from an idea or design supported by knowledge. developed by other elements together, improving the overall result.

Thus, the discussion review of the sources showed that the humanitarian quantorium as a technological digital environment for the competencies of the future teacher of history and social studies is being dynamically developed in the world scientific community, but many of its aspects remain unexplored.

\section{Conclusions}

This article attempts to substantiate the need to develop technologies for humanitarian education in a rapidly changing world, when digital technologies in education are supported at the state level and by the general public, and the development of technology for an effective way of teaching remains at the same level. In the current situation, the concept of a new educational environment is proposed, the "portfolio" of relevant competencies and the necessary methods and techniques of active interaction are specified.

In the context of digitalization of the content of education, the list of necessary competencies of the future teacher of history and social studies should be revised. The transformation of society enhances the process of differentiation and specialization. Innovations in digital learning are not so much technical innovations as changes in the content and organization of educational content, in the structure and organizational principles of learning. The latest data analysis techniques will open up new ways of understanding teaching. The integration of digital methods into the traditional learning process requires a restructuring of both the learning environment itself and a reassessment of opportunities. This environment defines the pedagogical quantorium,

The pedagogical quantorium as a technological digital environment for the competencies of the future teacher of history and social studies is introduced into scientific circulation for the first time. Pedagogical quantorium implies an information and educational environment for digital education, including: technical resources; educational resources; process control.

The emergence of quantorium in pedagogical universities will not only contribute to ensuring the quality of training of the future teacher, but will also create a modern system of continuous education for teachers, in particular, teachers in history and social science; expand interaction with general education organizations through additional education programs for a specific training profile, attract motivated applicants and transform the model of interaction with partner base schools.

In further research prospects, issues of the franchise of humanitarian quantoriums, which will become the basis for the formation of "children's" science, will be considered.

Future research will focus on participation in these projects, which will require innovative ideas and solutions capable of creating alternative solutions and forms of a technological digital environment, including discussions about the competencies of the future history and social science teacher. 


\section{References}

1. S. Philippe, A.D. Souchet, et.al.,Multimodal teaching, learning and training in virtual reality: a review and case study, Virtual Reality \& Intelligent Hardware 2(5), 421—442 (2020) DOI: 10.1016/j.vrih.2020.07.008

2. Z. Koukopoulo, D. Koukopoulos, Integration of educational theories into a possible digital environment, Applied Computing and Informatics 15, 19-26 (2019) https://doi.org/10.1016/j.aci.2017.09.004

3. B. Olszewski,H. Crompton,Educational technology conditions to support the development of digital age skills, Computers\&Education 150, 103849 (2020) https://doi.org/10.1016/j.compedu.2020.103849.

4. A. Hawlitschek,S. Joeckel,Improving the effectiveness of digital educational games: the impact of instructional instructions on learning, motivation and cognitive load of students, Computers in Human Behavior 프, 79-86 (2017) https://doi.org/10.1016/j.chb.2017.01.040

5. Q. Song, L. He,X. Hu,Increase the interactivity of educational history games through digital interactive storytelling,Physics Procedia $\underline{\mathbf{3 3}}, \mathbf{1 7 9 8 - 1 8 0 2}$ (2012) https://doi.org/10.1016/j.phpro.2012.05.287.

6. S. Janakiraman, S.L. Watson, W.R. Watson, T.NewbyLearning,Effectiveness of digital games in producing environmentally friendly attitudes and behaviors: A mixed methods study,Computers \& Education 160, $104043 \quad$ (2021) https://doi.org/10.25394/PGS.13356692

7. Education to Employment: Getting Europe's Youth into Work. McKinsey \& Company, January 2014. https://www.mckinsey.com/industries/public-and-social-sector/ourinsights/converting-education-to-employment-in-europe

8. R.I. Zekrist, Synergistic extension of the method of cultural studies,LAP LAMBERT Academic Publishing, Germany https://www.morebooks.shop/store/gb/book/synergistic-extension-of-the-method-ofcultural-studies/isbn/978-613-9-95489-6

9. E. Cassirer,Experience about man, Manandculture, Man 3, 93-105 (1990)

10. Communication trends in the post-literacy era: polylingualism, multimodality, polyculturalism, Fourth International Scientific and Theoretical Conference. Ekaterinburg (2019) http://www.kon-ferenc.ru/konferenc25_09_19_3.html.

11. Ch. Fadel, M. Bialik, B. Trilling,Four-Dimensional Education: The Competencies Needed for Success(M .: Publishing group "Tochka", 2018)

12. I. Ivanov,J.C. Cobo,M. Kosonogova, Implementation of developmental learning in a digital learning environment. Procedia Computer Science 172,517-522 (2020) https://doi.org/10.1016/j.procs.2020.05.062

13. M.G. Sorokova,Skepticism and Digital Learning Difficulties at Bachelor's and Master's Levels: Are Biases True?Heliyon, 6, 11, E05335 (2020) DOI:https://doi.org/10.1016/j.heliyon.2020.e05335

14. E.Neupokoeva, N.Chapaev, I.Suslova, N.Khokhlova, A.Sosnin,Formation of systems thinking among freshmen studying online at a professional pedagogical university, while mastering the basics of working with digital technologies, Thinking Skills and Creativity $\underline{\text { 39, }} 100753$ (2021) https://doi.org/10.1016/j.tsc.2020.100753

15. C.N. Prilop, K.E. Weber, M. Kleinknecht,Impact of the digital video feedback environment on the competence of teachers before starting to work in the field of 
feedback, Computersin Human Behavior 느, 120-131

https://doi.org/10.1016/j.chb.2019.08.011

16. P. Psomos,M. Kordaki,A novel educational digital storytelling tool aimed at eliminating student misconceptions, Procedia - Social and Behavioral Sciences $\underline{191}$, 8286 (2015)https://doi.org/10.1016/j.sbspro.2015.04.476

17. Q. Song,L. He,X. Hu,Increase the interactivity of educational history games through digital interactive storytelling,Physics Procedia $\underline{\mathbf{3 3}}, \mathbf{1 7 9 8 - 1 8 0 2 ( 2 0 1 2 )}$ https://doi.org/10.1016/j.phpro.2012.05.287

18. C. Holotescu,G. Grosseck,E. Danciu, 140 Character Educational Digital Stories: Toward a Microblogging Typology of Storytelling in Academic Courses, Procedia Social and Behavioral Sciences $\underline{\mathbf{1 1 6}}, 4301-4305$ (2014)https://doi.org/10.1016/j.sbspro.2014.01.936

19. M. Kordaki,On the design of educational digital stories: the Ed-W model,Procedia Social and Behavioral Sciences 116, 1631-1635 (2014)https://doi.org/10.1016/j.sbspro.2014.01.447

20. P. Brusilovsky,L.N.Cassel,L.M.L. Delcambre,E.A.Fox,R. Furuta,D.D.Garcia,F.M. Shipman III,M. Yudelsona,Social navigation for educational digital libraries, ProcediaComputerScience $\underline{1}, \quad 2$, 2889-2897 (2010)https://doi.org/10.1016/S18770509(10)00330-3

21. B. Mayer,D. Tantscher, Christian Bischof. From a digital store to real-time reporting: a case study for an IIoT-based educational use. Procedia Manufacturing 45,473-478 (2020) https://doi.org/10.1016/j.promfg.2020.04.055

22. A. Viloria,O.Bonerge, P. Lezama, N. Mercado-Caruzo, Factors describing the use of digital devices in Latin American universities, Procedia Computer Science 175, 127134 (2020) https://doi.org/10.1016/j.procs.2020.07.021

23. C. Papi,Digital Spaces: Between Educational Tools and Students, Procedia - Social and Behavioral Sciences https://doi.org/10.1016/j.sbspro.2015.01.1110

174, $\quad 3757-3764$ (2015)

24. S. Paulo, M. Lopes, J.S.B. Martins, Strategic Knowledge Management in the Digital Environment: Implicit and Explicit Knowledge in FabLabs, Journal of Business Research 94, 353-359 (2019) DOI: 10.1016/j.jbusres.2018.01.061 